\title{
THE INFLATION-CATHETER TECHNIQUE OF VENTILATION DURING LARYNGOSCOPY
}

\author{
JoliN S. GILliCK ${ }^{*}$
}

Since the intronuction uy SANDERs ${ }^{1}$ of the injector adaption to the ventilating bronchoscope, in 1967, there has been a tremendous proliferation of techniques utilizing high-flows of gases for ventilation during both bronchoscopy and laryngoscopy. Carden's' introduction of a catheter-injection technique for infant laryngoscopy opened the first practical application of this high-flow principle for the laryngoscopist. In 1974, the Inflation-Catheter Technique," was described for bronchoscopy and suggested for other oral endoscopies by adaptation of Carden's infant catheter to adults. The present article is a description of the InflationCatheter Technique (ICT) as it has now been employed for three years for the ventilation of adults and children during general anaesthesia for diagnostic and operative laryngoscopy.

\section{METHOD}

\section{General Principle}

The patient undergoing either diagnostic or operative laryngoscopy is given a "balanced" general anaesthetic consisting usually of a barbiturate, muscle relaxant, nitrous oxide, narcotic and/or diazepam. Throughout the procedure, the patient's ventilation is controlled by intermittent intratracheal inflation by approximately $10 \mathrm{ml} / \mathrm{kg} / \mathrm{sec}$ of gas for one to two seconds through a small uncuffed tracheal catheter. The gas is either oxygen or a selected mixture of nitrous oxide and oxygen. Air is not entrained. The patient exhales passively through his trachea past the catheter. The minute volume is determined by the ventilatory rate, the duration of the inspiration and the gas flow rate (litres per second) as limited by the internal cliameter and length of the specific inflation catheter and the driving pressure of the gas.

\section{Apparatus}

1. Gas Source. A high pressure gas source is required ( 2.5 to $4.0 \mathrm{~atm} ; 40$ to $60 \mathrm{psi}$ ) capable of delivering a flow of one or more litres per second sustained for tivo seconds. The source may be oxygen alone or a nitrous oxide-oxygen mixture drawn from high flow sources of each gas through a Bird Nitrous Oxide/Oxygen Blender.

\footnotetext{
-Staff Anesthesiologist, Anesthesia and Operative Services, Letteman Amy Medical Center, The Presidio of San Francisco, California 94129, U.S.A.

The opinions expressed by the writer herein are his own and may not be considered an official expression of the Department of the Army, U.S.A.
} 


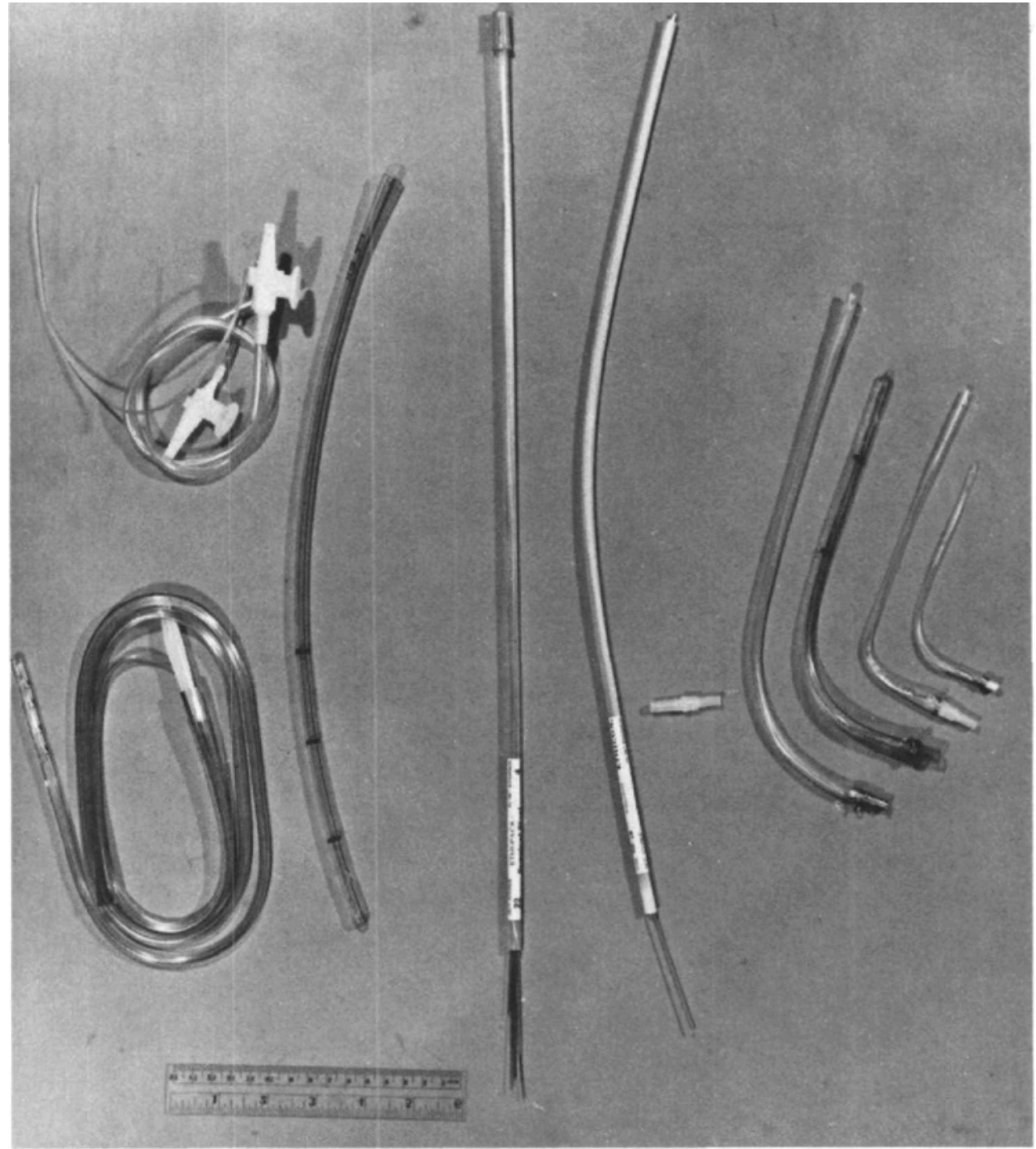

Figure 1. Material used in the construction of varions sized inflation catheters.

2. Pressure Regulator. The flow (litre per second) at the distal end of the catheter is a function of the driving pressure of the gas modified by the resistances (tubing diameter and length, connectors, and the inflation-catheter). All components should be comnected by tubing of $5 \mathrm{~mm}$ or greater internal diameter. Connectors and valves with tiny orifices should not be used. The inflation flow is then widely variable by regulation of the source gas by a pressure-reducing valve (described elsewhere" in detail), a needle valve, or even a screw clamp.

3. Rate control. The rate and duration of ventilation are controlled manually by an off-on button; or ventilation may be automatically cycled by comnection through the Wolf Injectomat 2025.

4. Inflation catheter. The tracheal inflation catheter may be fashioned from a 


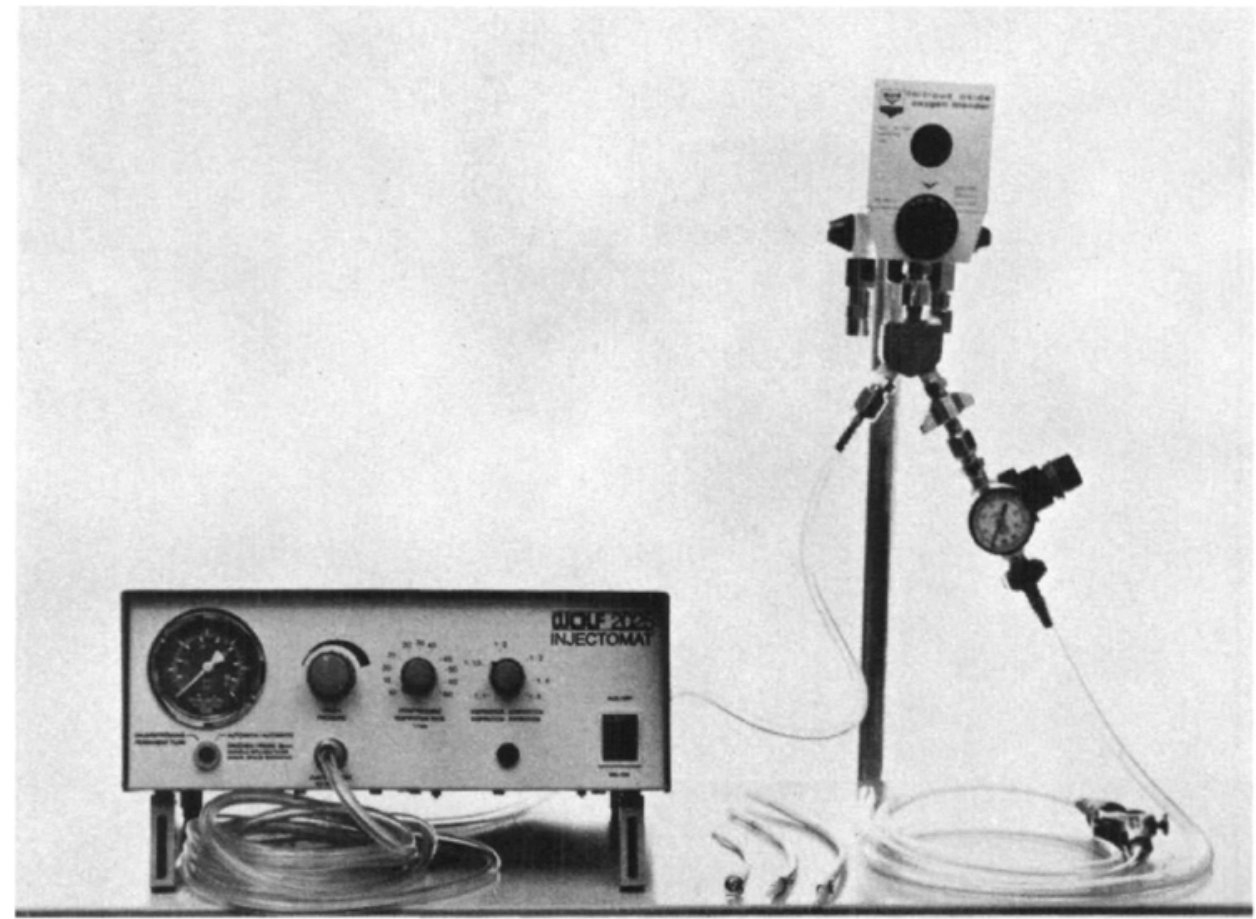

Figure 2. Injection apparatus. High pressure gas is delivered from the $\mathrm{N}_{2} \mathrm{O} / \mathrm{O}_{2}$ Blender (upper right), through a pressure regulator with off-on button (lower right), or through an automatic ventilator (lower left), into the inflation-catheter.

double-lumened nasogastric or "Salem sump" tube. The tube is cut to a length of $30 \mathrm{~cm}$ to $45 \mathrm{~cm}$, the distal end is cut to leave a side port and smoothed off to make it non-traumatic. The proximal end of the large lumen is fitted with a plastic hub from an intravenous infusion set. An 18- to 20-gauge surgical steel wire is threaded in the small lumen to within one $\mathrm{cm}$ of the distal end of the catheter. The proximal end of the steel wire is fixed by winding it around the plastic hub. The steel wire provides the rigidity needed to keep the catheter in position. A \#12 French tube is appropriate for patients weighing less than $40 \mathrm{~kg}$; \#14 French, for $40-60 \mathrm{~kg}$; \#16 French, for 60-80 kg; and \#18 French, for greater than $80 \mathrm{~kg}$.

However, any appropriately sized plastic catheter may be used. Stiffness may be maintained by fitting the steel wire in the single lumen. A \#7 French feeding tube with intralumenal wire would be appropriate for a child weighing $5-10 \mathrm{~kg}$ while a $\# 14,5^{1 / 2}$ inch Angiocath is appropriate and stiff enough for use in a smaller child or neonate.

5. Technique. General anaesthesia is induced by either an intravenous or an inhalation technique. The patient is paralyzed. Under direct laryngoscopy, the oral inflation catheter is inserted between the cords and approximately half the distance to the carina. The catheter is fixed to the side of the mouth and connected to the inflation device. Ventilation is maintained at a rate of 6 to 12 times per minute. Source pressure is initiated at about one atm (15 psi) and then regulated to a level that achieves a visible excursion of the thoracic cage, with a one- to two-second 


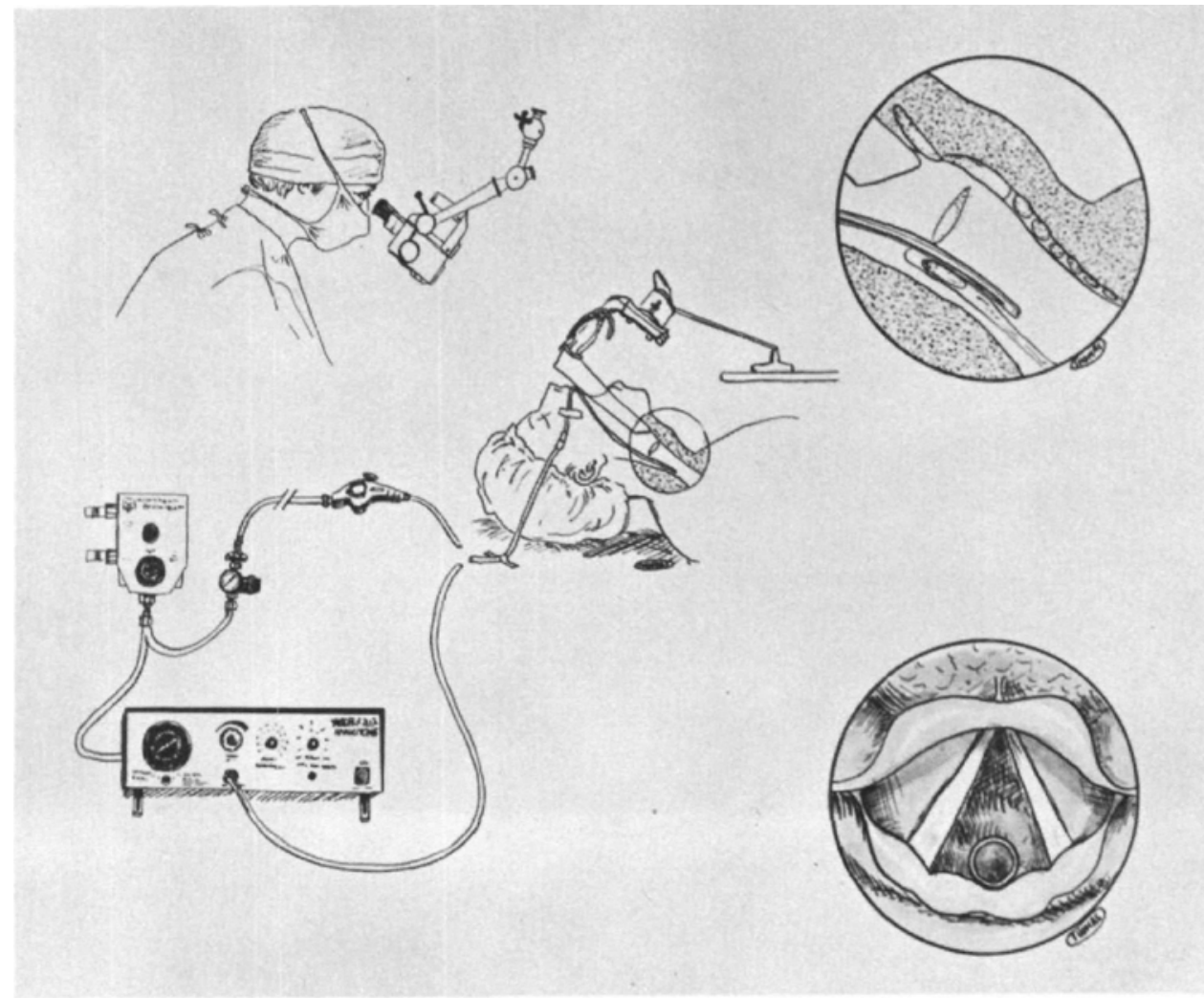

Figure 3. Inflation apparatus (lower left) regulates the anaesthetic gas into the patient's trachea (centre). The suspension laryngoscope is held by a Lewy holder which rests on a platform above the patient's chest. Upper right and lower right represent sagittal and transverse views of the upper trachea with the inflation-catheter in place.

inflation (usually about $1.5 \mathrm{~atm}$ ). Paralysis with controlled ventilation is maintained throughout the laryngoscopy. With termination of the procedure, the anaesthetic and paralysis are discontinued. The patient's ventilation may be assisted with the inflation-catheter at a lower source pressure until he is capable of strong spontaneous ventilation.

\section{Patients}

During the past three years arterial blood gases were measured in 50 of our patients having general anaesthesia with the inflation-catheter technique (ICT) for laryngoscopy. All 50 patients studied are included. Selection of patient and anaesthetist ( 16 participated) were strictly random. In 20 of the patients, control blood gas determinations were done while the patients breathed room air. Arterial samples for measurement of blood gases were drawn at ten-minute intervals after oral-tracheal intubation with the inflation catheter. Thirteen of the patients had bronchoscopy and/or oesophagoscopy under the Inflation Catheter Technique in conjunction with the laryngoscopy. The starting time for ten-minute blood gas intervals in these patients is at the start of the laryngoscopy. 


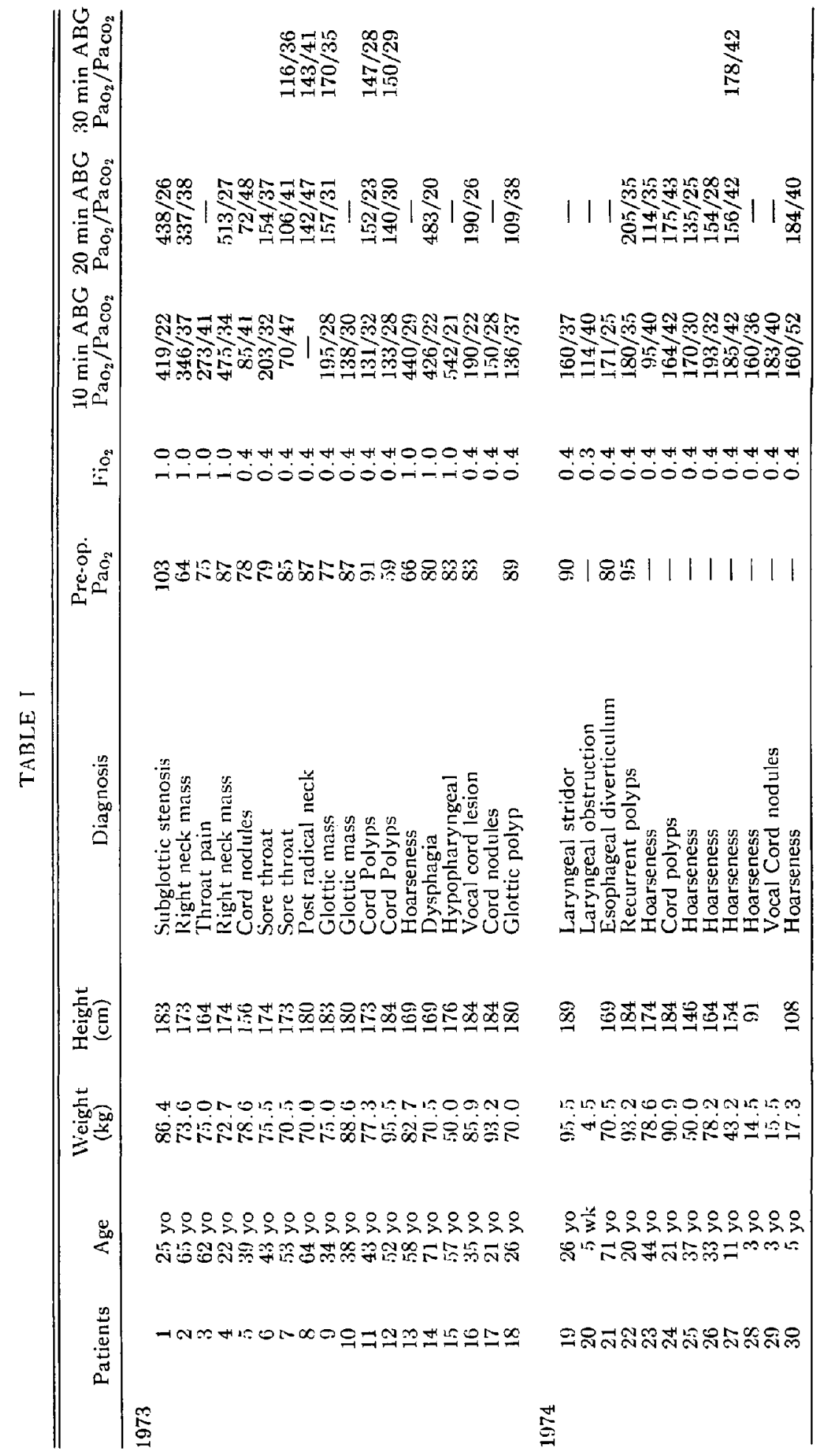


GILLICK: INFLATION-CATHETER TECHNIQUE

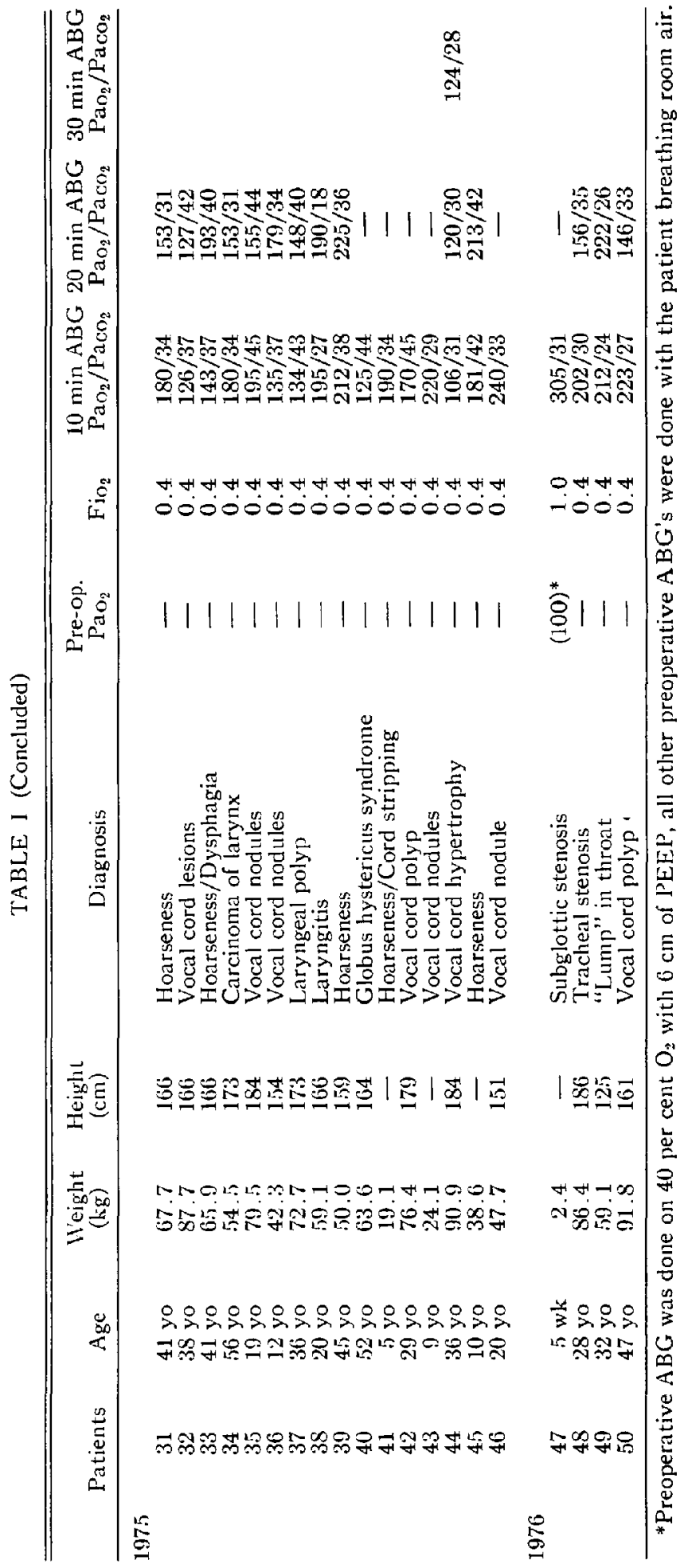




\section{RESULTS}

Data from all the patients studied including arterial blood gases are listed in Table I. Eight patients were ventilated with 100 per cent oxygen, achieving a mean $\mathrm{Pa}_{\mathrm{O}_{2}}$ of 416 torr ( $\mathrm{SD} \pm 84$ ) and $\mathrm{Pa}_{\mathrm{CO}_{2}}$ of 29 torr $(\mathrm{SD} \pm 7$ ). Forty-one patients were ventilated with 40 per cent oxygen mixed with 60 per cent nitrous oxide, achieving a mean $\mathrm{Pa}_{\mathrm{O}_{2}}$ of $161(\mathrm{SD} \pm 36)$ and $\mathrm{Pa}_{0_{2}}$ of $35(\mathrm{SD} \pm 7)$. One child (patient no. 27) was ventilated with 30 per cent oxygen with nitrous oxide.

Thirteen of these patients had bronchoscopy and/or oesophagoscopy in addition to laryngoscopy during the same ICT anaesthetic. Arterial blood gases during these additional procedures were essentially the same in a given patient regardless of the procedure. None of these or any other of our laryngoscopy patients have suffered any complications during ventilation by the ICT.

A Lewy support held the suspension larynoscope and was braced on the patients' chests in cases No. 5 and No. 7. This resulted in restriction of the thoracic excursion and lower $\mathrm{Pa}_{\mathrm{O} .}$. This was avoided in subsequent patients by resting the Lewy laryngoscope holder on a Mayo stand above the chest.

Patients No. 23, 32, 40 and 44 did not have a good visible excursion of the thoracic cage with inspiration. This could have been avoided by ventilation with a higher driving pressure, by use of a longer inflation time, or by employment of a larger diameter catheter. Although $\mathrm{Pa}_{\mathrm{CO}_{2}}$ could be readily lowered by rapid ventilation, $\mathrm{Pa}_{\mathrm{O}_{2}}$ levels were positively correlated with the thoracic and diaphragmatic excursion obtained. Patient No. 38 was ventilated at 20 breaths/min for three minutes prior to his 20-minute arterial blood gases. Patients No. 43 and 46 were purposefully hyperventilated with three to four second inspirations with excellent thoracic and diaphragmatic excursion, at a rate of six per minute for six minutes before blood gas sampling.

Patients No. 47, 48, 49, and 50 were ventilated entirely with the Wolf Injectomat 2025 through the inflation-catheter during laryngoscopy. Patient 48 had a subsequent two-hour period of controlled ventilation (with the Wolf Injectomat) through the orotracheal inflation-catheter during a tracheal resection.

\section{Discussion}

\section{Techniques}

Multiple techniques have been employed in the search for a simple, yet safe technique for ventilation of patients during operative laryngoscopy which will allow optimal surgical exposure and yet permit the anaesthetist to retain control of the airway.

These techniques might be summarized as follows:

1. Apnoeic and sharing the airway techniques. With these techniques the patient is deeply anaesthetized, and either paralyzed or spontaneously inhaling volatile anaesthetics while the laryngoscopist and the anaesthetist exchange control of the airway. Although these methods are quite adequate for brief examinations, they are clumsy and do not allow safe use of a suspension laryngoscope, safe microlaryngeal surgery or prolonged operations.

2. Small cuffed tracheal tube technique. This technique has the advantage of continuous airway access for the anaesthetist and allows use of the suspension 
laryngoscope. It has dual disadvantages of being a relatively high resistance system requiring prolonged exhalation with less than optimal carbon dioxide elimination, and of being cumbersome for the surgeon to work around.

3. The jet operating laryngoscopy. ${ }^{+5}$ In this technique, oxygen is jetted down the trachea past the tip of the suspension operating laryngoscope. The oxygen stream entrains air through the patient's mouth into his trachea with a resulting volume of oxygen and air sufficient for controlled ventilation. The disadvantages are obvious. Airway control and ventilation are dependent upon the surgeon, not the anaesthetist; air is entrained, resulting in an unpredictability of inspired oxygen concentration; and the forceful gas flow past the operative site down the trachea can allow entrainment of oral or operative debris along with the air.

4. Transtracheal techniques. In these, a bent needle or cannula is inserted percutaneously into the trachea and a high pressure gas source is used for ventilation. The first objection is to the invasive nature of the technique. Percutaneous tracheal cannulation is not a technique most anaesthetists would feel comfortable in performing. If the needle or cannula is of insufficient size, as is almost always the case, air entrainment through the mouth will occur during inspiration with dilution of the ventilating gas and possible entrainment of debris.

5. Carden Jet Tube. This technique incorporates a chopped-off tracheal tube to hold an inflation catheter below the larynx. With proper use air and tracheal debris are not entrained, except in the largest patients, and the surgeon is given excellent operating conditions. Objections are to the inconvenience and sometimes the difficulty of placement and extraction of the infralaryngeal cylinder (tube). The Carden tube is quite difficult to remove from the patient whose paralysis is wearing off. It cannot be used to assist ventilation of the wakening patient.

6. Inflation-catheter techniques. Use of a semi-rigid inflation-catheter is described previously ${ }^{2 . .3 .1}$ and in this report. Techniques other than the use of a stiffened semi-rigid inflation-catheter have been described for catheter inflation ventilation, such as a nasotracheal catheter ${ }^{7}$ or an intermittent cuff technique; ${ }^{10}$ but these prove troublesome to place and to maintain during ventilation. Air entrainment techniques ${ }^{11}$ make it difficult to use nitrous oxide predictably as an adjuvant anaesthetic agent.

\section{The Ideal InfLation-Catheter}

What distinguishes the Inflation Catheter Technique is the inflation-catheter. This catheter may be of many designs or lengths but must meet several criteria:

(a) It must be stiff enough to keep from being "blown-out" of the trachea during insufflation. This stiffness may be produced by fixation of an intralumenal wire.

(b) It should have no sharp projections to harm the trachea.

(c) It should have extra terminal side holes to allow alternate routes for gas escape in event that the tip of the catheter is occluded.

(d) It should be rigid enough that it will not be easily closed off by pressure from the laryngoscope, bronchoscope or operating instruments.

(e) Multiple sizes should be available. It must be small enough to be out of the surgeon's way, yet have an adequate internal diameter to allow passage of $10 \mathrm{ml} / \mathrm{kg} / \mathrm{sec}$ for the given patient. 
(f) It should be clear plastic to be less obtrusive in the posterior fornix and it should have permanent marks two to three $\mathrm{cm}$ from the distal tip to allow for accurate placement.

\section{As a general endoscopic technique}

We and others ${ }^{12}$ have employed the Inflation Catheter Technique with the flexible fiberoptic bronchoscope generally with an oral tracheal tube guide for the bronchoscope, and with the rigid bronchoscope and oesophagoscope in addition for laryngoscopy over the past three years.

The technique has been used safely by the orotracheal route for ventilation during operative resection of a tracheal stenosis ${ }^{13}$ and resection of tracheal malacia (patient \#48 at a later time).

With rigid bronchoscopy, there is a potential hazard that an uninitiated surgeon can use a very snug bronchoscope, can occlude the exhalation port of the scope with his thumb, or can impinge the inflation-catheter agianst the tracheal wall. Any of these, undetected by the anaesthetist, could result in a pneumothorax or pncumomediastinum. These hazards do not generally apply except in rigid bronchoscopy. Therefore, the Inflation Catheter Technique must be more strongly recommended in endoscopics other than rigid bronchoscopy.

\section{Automatic Ventilation}

As with any other anaesthetic technique involving controlled patient ventilation, it is useful for the anaesthetist to have his hands free. We have experimented with a knee switch and with a foot switch but the most satisfactory so far has been the employment of the Wolf Injectomat 2025 for automatic ventilation. With it the ratc, pressure and inspiratory-expiratory ratios can be set. This allows for predictable and casily controlled minute volumes.

\section{SUMMARY}

Over the past three yenrs the inflation-catheter technique (ICT) of controlled ventilation during general ancesthesia has proved a safe and useful method for use with laryngoscopy and other trans-oral endoscopies (most notably flexible fiberoptic bronchoscopy). The ICT allows full control of the patient's airway for the anaesthetist and exceptionally good exposure for the surgeon.

In this technique ventilation of the patient is accomplished by intermittent high flow ( $10 \mathrm{ml} / \mathrm{kg} / \mathrm{sec}$ ) inflation of the lungs through a small (2 to $6 \mathrm{~mm}$ diameter) plastic orotracheal catheter. The inflation-catheter is stiffened by fixation of an intralumenal wire. Exhalation is passive around the catheter through the open airway.

The Inflation Catheter Technique is readily adaptable for patients ranging from large adults to small babies by variation of catheter sizes. It can be used safely with nitrous oxide-oxygen as the ventilating gas (i.e., Bird $\mathrm{N}_{2} \mathrm{O} / \mathrm{O} . \mathrm{B}$ Blender) since air entrainment is not a feature. It is also readily adaptable for use with mechanical ventilation (i.e., Wolf Injectomat). 


\section{RÉSUMÉ}

Une technique permettant linsufflation intermittente d'un jet de gaz travers un cathéter a été ultilisée avec succès depuis trois ans, ceci pour les cas de laryngoscopie, et pour les autres endoscopies, en particulier pour les bronchoscopies avec un bronchoscope flexible Fibre-Optique. Cette méthode permet à l'anesthésiste d'avoir un contrôle complet de la ventilation tout en fournissant un champ excelient au chirurgien.

La ventilation est assurée au moyen d'un jet intermittent, soit $10 \mathrm{mls} / \mathrm{kilo}$ de gaz insufflés à haut débit via un cathéter orotrachéal de petit calibre ( 2 à $6 \mathrm{mms}$ ).

Un fil d'acier inoxydable glissé dans la lumière du tube jusqu’à $1 \mathrm{~cm}$ de son extrémité distale rend le cathéter assez rigide pour en faciliter la manipulation. L'expiration est passive et se fait au pourtour du cathéter.

En variant le diamètre du tube endotrachéal, cette technique est applicable tant aux bébés qu'aux adultes. Ellle pcut être utilisée avec un mélange de Protoxyde d'Azote et d'Oxygène (au moyen d'un mélangeur de Protoxyde d'Azote-Oxygène). On peut même s'en servir avec un ventilateur mécanique (Injectomat de Wolf).

\section{EquipMENT}

1. Bird $\mathrm{N}_{2} \mathrm{O} / \mathrm{O}_{2}$ Blender \#992902: Bird Corporation, Palm Springs, California, 92262 (U.S.A.).

2. Wolf Injectomat 2025 (modified for high gas flow): Richard Wolf GMBH, 7134 Knittlingen (West Germany); Wolf Medical Instruments, 7046 Lyndon Ave., Rosemont, Illinois, 60018 (U.S.A.); Downs Surgical, 26 Davenport Rd., Toronto, Ontario M5R 1K3 (Canada); Downs Surgical, Church Path, Mitchem, Surrey CR4 3UE (England); Downs Surgical, 575 George St., Sydney, N.S.IV. 2000 (Australia).

3. Angiocath; Deseret Pharmaceutical Co., Inc., Sandy, Utah 84070 (U.S.A.).

\section{ACKNOWLEDGMENTS}

The author wishes to thank Ms. B. Balance and the Inhalation Therapy Staff of the 97th General Hospital for arterial blood gas analysis; Ms. J. Levin, Ms. J. Vandergriff and Ms. B. King for preparation of the manuscript; Ms. Thomas for the medical illustrations and Sgt. Powell for the photography.

\section{REFERENCES}

1. Saxiders, R.D. Two ventilating attachments for bronchoscopes. Del. Med. 1. 30: 170 (1967).

2. Camben, E. \& Fercuson, C.B. A new technique for micro-laryngeal surgery in infants. The Laryngoscope 93: 691-699 (1973).

3. Cilluck, J.5. The inflation-catheter technique for ventilation during bronchoseopy. Anesthesiology, 40: 503-6 (1974).

4. AlBERT, S.N. The Albert-Sinders adaptor for ventilating anaesthetized patients for microlaryngcal surgery. Brit. J. Anaesth. 43: 1098 (1971). 
5. Oultox, J.L. \& Donald, D.M. A ventilating laryngoscope. Anesthesiology 35: 540-542 (1971).

6. Spoenel, W.E., Narayanax, P.S., \& Singh, N.P. Transtracheal ventilation. Brit. J. Anaes. 43: 932 (1971).

7. Spoelrel, W.E. \& Gheenway, R.E. Technique of ventilation during endolaryngeal surgery under general anesthesia. Canad. Anaes. Soc. J. 20:369-377 (1973).

8. Calnes, E. \& Crutchfield, W. Anesthesia for microsurgery of the larynx. Canad. Anacs. Soc. J. 20:378-389 (1973).

9. CillulCK, J.S. A new technique of anaesthesia for laryngoscopy and bronchoscopy, No. 330, IV European Congress of Anaesthesiology, Madrid, Sept. 5-11, 1974 (Eds. Arias, A., Llaurdo, R., Nalda, M.A., \& Lunn, J.N.), p. 211. Amsterdam: Excerpta Medica (1974)

10. El-Nagcer, M., Kerl E., Stemmers, A., \& Collin, V.J. Jet ventilation for microlaryngoscopic proceclures: a further simplified technique. Anes, \& Analg. 53: 797-804 (1974).

11. Simti, R.B., Babisski, M., \& Petruscak, J. A method of ventilating patients during laryngoscopy. The Laryngoscopy, $84: 553$ (1974).

12. Macxauchton, F.I. Anaesthesia for fiberoptic bronchoscopy. Brit. J. Anaes. 47: 1219-23 (1975).

13. Macnauchtox, F.I. Catheter inflation ventilation in tracheal stenosis. Brit. J. Anaes. 47: 1225-7 (1975). 